\title{
FAKTOR UTAMA YANG MEMPENGARUHI NASABAH DALAM MENGAMBIL KREDIT DI BANK PERKREDITAN RAKYAT (BPR) KOTA KEDIRI
}

\author{
Edy Djoko Soeprajitno ${ }^{1)}$ Wawan Herry Setyawan ${ }^{2)}$ Dhiyan Septa Wihara ${ }^{3)}$ \\ 1)Fakultas Ekonomi Universitas Nusantara PGRI Kediri \\ Email : edydjoko.s@gmail.com \\ 2)Fakultas Keguruan Ilmu Pendidikan Uniska Kediri \\ Email : wawansetyawan225@gmail.com \\ 3) Fakultas Ekonomi Universitas Nusantara PGRI Kediri \\ Email : dhiyansepta@gmail.com
}

\begin{abstract}
One of the objectives of credit is to move the wheels of the regional economy. Especially for the small and medium enterprises (SMEs) trade and micro sector, which is now booming because it can improve the household economy. Various financial institutions offer various types of loans with attractive facilities and according to the needs of the target market. Therefore, today's society is demanded to be smart in accessing credit at bank financial institutions. Including the People's Credit Bank (BPR) Kota Kediri which also competes in offering loans that are in accordance with the wishes of the people in the Kediri region and its surroundings. The sample used in this study amounted to 97 customers. This study uses a quantitative approach with factor analysis techniques using principal component analysis (PCA). The result is that there are six groups of factors that influence customers in taking credit with a cumulative diversity value of 59,671. Factor I consists of variations in time period, loan nominal and service has an eigenvalue of 2.935 and total diversity value of $18.343 \%$. Factor II consisted of reasons for interest rates, repayment deductions and requirements having an eigenvalue of 1.590 and a total diversity of $9.936 \%$. Factor III consisted of variations in interest rates and flexible time periods having eigenvalues of 1.552 and total diversity of $9.701 \%$. Factor IV consists of a credit process and the service schedule has an eigenvalue of 1.2282 and a total diversity of 8.014. Factor V consists of loans as needed and flexible guarantees have an eigen value of 1.165 and a total diversity of 7.284. Factor VI is a lack of requirements following with an eigen value of 1.023 and a total diversity of 6.394 .
\end{abstract}

Key words : Decision on taking credit, Factor Analysis, BPR in Kediri City

\begin{abstract}
Abstrak
Salah satu tujuan dari kredit adalah menggerakkan roda perekonomian daerah. Terutama untuk sector perdagangan dan usaha mikro kecil dan menengah (UMKM) yang sekarang mulai booming karena dapat meningkatkan ekonomi rumah tangga. Berbagai lembaga keuangan menawarkan jenis kredit yang bermacam-macam dengan fasilitas yang menarik dan sesuai dengan kebutuhan pasar sasaran. Oleh karenanya masyarakat sekarang ini dituntut cerdas dalam mengakses kredit pada lembaga keuangan bank. Termasuk Bank Perkreditan Rakyat (BPR) Kota Kediri yang juga ikut bersaing dalam menawarkan kredit yang sesuai dengan keinginan masyarakat diwilayah Kediri dan sekitarnya. Sampel yang digunakan dalam penelitian ini berjumlah 97 nasabah. Penelitian ini menggunakan pendekatan kuantitatif dengan teknik analisa faktor menggunakan principal component analysis (PCA). Haslnya adalah ada enam kelompok faktor yang mempengaruhi nasabah dalam mengambil kredit dengan nilai keragaman komulatif sebesar 59,671. Faktor I terdiri dari variasi jangka waktu, nominal pinjaman dan pelayanan memiliki nilai eigen 2,935 dan nilai keragaman total sebesar 18,343\%. Faktor II terdiri dari alasan suku bunga, potongan pelunasan dan persyaratan memiliki nilai eigen 1,590 dan keragaman total sebesar 9,936\%. Faktor III terdiri dari variasi suku bunga dan jangka waktu fleksibel memiliki nilai eigen 1,552 dan keragaman total sebesar $9,701 \%$. Faktor IV terdiri dari proses kredit dan jadwal pelayanan memiliki nilai eigen 1,282 dan keragaman total sebesar 8,014. Faktor V terdiri dari pinjaman sesuai kebutuhan dan jaminan fleksibel memiliki nilai eigen 1,165 dan keragaman total sebesar 7,284. Faktor VI adalah kekurangan persyaratan menyusul dengan nilai eigen 1,023 dan keragaman total sebesar 6,394.
\end{abstract}

Kata kunci : Keputusan mengambil kredit, Analisis Faktor, BPR Kota Kediri. 


\section{JURNAL EKONOMI DAN MANAJEMEN \\ P-ISSN: 2598-9022/ E-ISSN: 2598-9618 \\ Available at: http://e-journal.unipma.ac.id/index.php/capital}

PENDAHULUAN

Permasalahan yang dihadapi

Usaha Mikro Kecil dan Menengah (UMKM) pada umumnya adalah masalah permodalan, SDM dan teknologi. Ketiga masalah tersebut menjadi tantangan tersendiri bagi UMKM untuk dapat bersaing dengan sector perdagangan lainnya. Namun dari ketiga permasalahan tersebut yang paling mendasar adalah masalah permodalan dimana ini merupakan kunci pokok sebuah UMKM dapat meningkatkan daya saingnya. Dengan modal yang kuat tentu UMK mdapat memiliki teknologi yang tepat sehingga bisa memangkas biaya produksi dan juga lebih efisien. Deputi bidang pembiayaan kementrian koperasi dan UKM Yuana Setyowati, mengatakan ada sekitar 62,9 juta pelaku usaha UMKM dan hanya sekitar $20 \%$ saja saja dari jumlah tersebut yang sudah bankable atau dapat mengakses pembiayaan melalui bank (www.merdeka.com). Sebagian UMKM yang belum bisa mengakses pembiayaan melalui bank inilah yang perlu ditelusuri penyebabnya karena hampir semua lembaga keuangan bank bersaing untuk menawarkan kredit pada UMKM. Terutama BPR yang memang tugas pokok dan fungsinya sebagai solusi permodalan untuk usaha mikro kecil dan menengah.

Setiap BPR harus memperhatikan model pembiayaan yang cocok untuk untuk usaha mikro dan kecil (UMK) agar mampu memperoleh nasabah yang banyak dari kalangan usaha kecil tersebut. model pembiayaan yang diinginkan UMKM adalah model pembiayaan yang melibatkan penyandang dana, lembaga keuangan formal (Bank) dan pembina atau koordinator (Silalahi,2013). Selain menghadapi persaingan dengan BPR swasta, BPR milik pemerintah daerah juga harus mengantisipasi perkembangan dari koperasi dimana memiliki bidikan pangsa pasar yang sama yaitu usaha kecil. Namun BPR setidaknya memiliki keunggulan dalam memberikan jenis produk yang variatif dan plafond pinjaman yang lebih besar.serta tingkat bunga yang variatif sehingga cocok untuk jenis usaha kecil dan menengah (Anam dan Nahar, 2015).

Menurut Suyanto dkk (2003) menyimpulkan beberapa faktor yang mempengaruhi nasabah dalam mengambil kredit adalah syarat kredit, kemudahan prosedur, jaminan yang lunak, suku bunga dan pelayanan. Beberapa factor tersebut memang sangat 


\section{JURNAL EKONOMI DAN MANAJEMEN \\ P-ISSN: 2598-9022/ E-ISSN: 2598-9618 \\ Available at: http://e-journal.unipma.ac.id/index.php/capital}

dipertimbangkan oleh nasabah disamping masing banyak juga faktor yang mempengaruhi keputusan mengambil kredit di bank. Saat ini nasabah sudah semakin cerdas dalam memilih bank, tidak sedikit dari mereka yang langsung menanyakan secara detail tentang fasilitas kredit yang ditawarkan oleh bank tersebut. Oleh karena itu petugas bank dituntut harus benar-benar menguasai tentang produk yang ditawarkannya karena ini merupakan bagian dari pelayanan. Jadi selain beberapa komponen pokok penting seperti suku bunga, jaminan besarnya pinjaman dan sebagainya factor pelayanan juga bisa mempengaruhi nasabah dalam mengambil kredit. Penelitian dari Bramantyo (2017) mempertegas bahwa kualitas pelayanan, prosedur dan promosi secara bersamasama berpengaruh positif dan signifikan terhadap keputusan pengambilan kredit di LKBB Kecamatan Salam Kabupaten magelang.

Berdasarkan uraian diatas dapat disimpulkan bahwa ada banyak sekali faktor yang digunakan nasabah dalam memutuskan untuk kredit di lembaga keuangan. Oleh karenanya bank harus berupaya meringkas beberapa faktor tersebut menjadi lebih spesifik.
Tujuannya tidak lain hanyalah untuk memberikan masukan kepada pihak manajemen untuk bisa fokus menciptakan produk yang sesuai dengan pasar sasaran. Disisi lain bagi pihak manajemen tentu juga akan lebih dini dalam mempersiapkan sumber daya manusia yang dapat menunjang kelancaran operasional dengan strategi yang baru tersebut mengacu dari faktor utama yang bisa mempengaruhi nasabah dalam mengambil keputusan kredit.

Bank Perkreditan Rakyat (BPR) Kota Kediri merupakan salah satu bank BPR yang ada diwilayah Kota Kediri dimana BPR ini melayani masyarakat wilayah Kediri terutama pada segmen UMKM karena kehadiran BPR menurut Bank Indonesia adalah dikhususkan pada masyarakat menengah khususnya UMKM. Apalagi jumlah UMKM diwilayah Kediri selalu mengalami peningkatan setia tahunnya. Menurut walikota Kediri yang dikutip pada koran memo (http://koranmemo.com/) menyebutkan bahwa Di Tahun 2018, Kota Kediri juga berhasil menekan angka kemiskinan Sebesar 7,68\%. Penurunan kemiskinan di Kota Kediri ini, berada di bawah capaian nasional sebesar 9,82\% dan capaian Jawa Timur sebesar 10,98\%. Ini menunjukkan bahwa 


\section{CAPITAL \\ JURNAL EKONOMI DAN MANAJEMEN \\ P-ISSN: 2598-9022/ E-ISSN: 2598-9618 \\ Available at: http://e-journal.unipma.ac.id/index.php/capital}

UMKM di Kota Kediri benar-benar menggeliat dan memiliki peran strategis dalam memerangi kemiskinan dan pengangguran dengan jumlahnya yang mencapai 38.806 usaha.

Fenomena diatas tentu harus direspon baik oleh pihak BPR Kota Kediri karena disisi lain meupakan peluang untuk menambah pangsa pasar diwilayah Kediri namun disisilain perlu diwaspadai artinya persaingan lembaga keuangan diwilayah Kediri semakin ketat. Oleh karena itu tujuan penelitian ini adalah untuk mengetahui alasan atau faktor yang paling utama dari nasabah untuk mengambil keputusan kredit di BPR Kota Kediri.

\section{METODOLOGI PENELITIAN}

\section{Rancangan Penelitian}

Pendekatan penelitian ini adalah kauntitatif. Merupakan metode penelitian yang berlandaskan pada filsafat positivisme, digunakan untuk meneliti pada populasi atau sampel tertentu (Sugiyono, 2013: 13)

Penelitian ini dilakukan di BPR Kota Kediri Jln. Ruko Brawijaya, Pocanan Kec. Kota Kediri Jawa Timur. Populasi dalam penelitian ini adalah seluruh nasabah yang kredit di BPR Kota Kediri dan jumlahnya tidak diketahui sehingga peneliti menggunakan rumus infinite sampling sebagai berikut.

$$
n=\frac{z^{2}}{4(m o e)^{2}}
$$

\section{Keterangan :}

$\mathrm{n} \quad=$ jumlah sampel

$\mathrm{Z}=$ tingkat keyakinan dalam penentuan sampel 90\% $=1,96$

Moe $=$ Margin of error atau kesalahan maksimum yang bisa ditoleransi, disini ditetapkan sebesar $10 \%$

Dengan dasar tersebut maka dapat dilihat ukuran sampel minimal yang harus dicapai dalam penelitian ini adalah sebesar :

$$
n=\frac{1,96^{2}}{4(0,1)^{2}}=96,04=97
$$

Berdasarkan rumus diatas, sampel yang dapat diambil dari populasi yang besar sebanyak 96,04 orang bila dibulatkan, maka banyaknya sampel adalah sebesar 97 responden.

\section{Definisi Operasional}

Untuk mempermudah dalam menginterpretasikan faktor agar bisa dipahami degan jelas maka disusun intrumen penelitian yang telah didefinisikan sebagai berikut. 


\section{CAPITAL \\ JURNAL EKONOMI DAN MANAJEMEN \\ P-ISSN: 2598-9022/ E-ISSN: 2598-9618 \\ Available at: http://e-journal.unipma.ac.id/index.php/capital}

Tabel 1. Indikator dan definisi

\begin{tabular}{|c|c|}
\hline Indikator & Definisi \\
\hline $\begin{array}{l}\text { Suku } \\
\text { bunga }\end{array}$ & $\begin{array}{l}\text { a. Suku bunga cukup rendah }(x 1) \\
\text { b. Suku bunga bervariasi }(x 2) \\
\text { c. Suku bunga menjadi alasan } \\
\text { utama dalam meminjam }(x 3)\end{array}$ \\
\hline $\begin{array}{l}\text { Jangka } \\
\text { waktu }\end{array}$ & $\begin{array}{l}\text { a. Jangka waktu yang fleksibel }(x 4) \\
\text { b. Variasi Jangka waktu }(x 5) \\
\text { c. Potongan pelunasan sebelum } \\
\text { jatuh tempo }(x 6)\end{array}$ \\
\hline Persya & $\begin{array}{l}\text { a. Persyaratan kredit mudah (x7) } \\
\text { b. Waktu menyerahkan persyaratan } \\
\text { yang fleksibel (x8) } \\
\text { c. Kelengkapan persyaratan } \\
\text { menyusul (x9) }\end{array}$ \\
\hline & $\begin{array}{l}\text { a. Jumlah pinjaman yang diberikan } \\
\text { cukup besar }(x 10) \\
\text { b. Jumlah pinjaman sesuai dengan } \\
\text { kebutuhan }(x 11) \\
\text { c. Jumlah pinjaman lebih besar } \\
\text { dibandingkan dengan BPR } \\
\text { lain/koperasi. }(x 12)\end{array}$ \\
\hline Jaminan & $\begin{array}{l}\text { a. Jaminan sepeda motor mulai dari } \\
\text { tahun lama masih bisa digunakan } \\
(x 13) \\
\text { b. Jaminan yang ditetapkan } \\
\text { bervariasi (BPKB, Sertifikat, Bilyet } \\
\text { Deposito dsb). (x14) } \\
\text { c. Jaminan disesuaikan dengan } \\
\text { kepemilikan dari nasabah (x15) }\end{array}$ \\
\hline $\begin{array}{l}\text { Pelayana } \\
\text { bank }\end{array}$ & $\begin{array}{l}\text { a. Proses kredit yang cepat (x16) } \\
\text { b. Pelayanan karyawan bank yang } \\
\text { ramah (x17) } \\
\text { c. Pelayanan jemput bola (x18) } \\
\text { d. Pelayanan kantor yang optimal } \\
\text { sesuai dengan jadwal (x19) } \\
\text { e. Respon karyawan yang cepat } \\
\text { dalam menanggapi masalah } \\
\text { nasabah }(x 20)\end{array}$ \\
\hline
\end{tabular}

Sumber : data primer, 2019

\section{Teknik Analisis Data}

Dalam penelitian ini digunakan analisis faktor. Analisis Faktor merupakan suatu teknik statistik multivariate yang digunakan untuk mengurangi (reduction) dan meringkas (summarization) semua variabel terikat dan saling berketergantungan. Hubungan ketergantungan antara satu variabel dengan yang lain yang akan diuji untuk diidentifikasikan dimensi atau faktornya. Prosedur analisis faktor adalah sebagai berikut.

1) Penentuan variabel yang akan dianalisis.

2) Menghitung matriks korelasi dengan metode Bartlett test of spericity sertapengukuran MSA (Measure of Sampling).

3) Proses Ekstraksi atau Factoring, menggunakan Principal Component Analysis(PCA).

4) Menentukan jumlah faktor yang paling berpengaruh dengan melihat nilai eigenvalue $>1$.

5) Merotasi faktor untuk memperjelas posisi suatu variabel dengan menggunakanmetode varimax.

6) Menginterpretasi faktor-faktor

\section{HASIL DAN PEMBAHASAN}

\section{Menilai Variabel yang layak}

Berdasarkan hasil analisa yang dilakukan pada software SPSS untuk 20 item pertanyaan dalam kuisioner yang dijawab oleh 97 responden diperoleh hasil yang disajikan dalam tabel 2 berikut ini. 


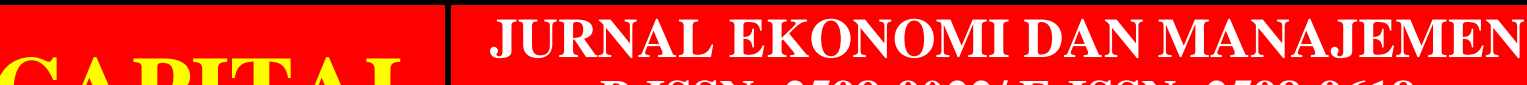 \\ P-ISSN: 2598-9022/ E-ISSN: 2598-9618 \\ Available at: http://e-journal.unipma.ac.id/index.php/capital}

KMO and Bartlett's Test

\begin{tabular}{|ll|r|}
\hline \multicolumn{2}{|l|}{ Kaiser-Meyer-Olkin Measure of } & .675 \\
Sampling Adequacy. & & \\
Bartlett's Test of & Approx. \\
Sphericity & Chi- & 201.911 \\
& Square & \\
& df & 120 \\
& Sig. & .000 \\
\hline
\end{tabular}

Tabel 2. KMO and Bartlett's Test

Sumber: data primer diolah, 2019

Berdasarkan tabel 2 diatas dapat

diketahui bahwa angka KMO and Bartlett's test adalah 0,675>0,5 dengan signifikansi 0,000 atau dibawah 0,05 maka variabel dan sampel sudah layak untuk dianalisa lebih lanjut dengan menggunakan analisis faktor.

\section{Anti Image Correlation}

Merupakan pengujian seluruh matriks korelasi (korelasi antar variabel) yang diukur dengan besaran Measure Sampling Adequacy (MSA).

Berdasarkan hasil pengolahan data yang dilakukan dapat diketahui bahwa nilai Measure Sampling Adequacy (MSA) untuk tahap pertama terdapat beberapa variabel yang nilai MSA nya kurang dari 0,5 yaitu variabel X1 (sukubunga rendah), variabel X8 (persyaratan fleksibel), Variabel X14 (jaminan bervariasi) dan variabel X15 (jaminan sesuai kepemilikan). Sehingga ke-empat variabel ini harus dikeluarkan dari analisis faktor tahap kedua.
Pada analisis faktor tahap kedua diperoleh nilai MSA untuk semua variabel diatas 0.5 hal ini berarti variabel masih dapat diprediksi untuk dianalisa lebih lanjut.

\section{Hasil Ekstraksi Faktor}

Analisis faktor dalam penelitian ini digunakan untuk mereduksi variabel kedalam beberapa komponen (faktor) . metode yang dgunakan adalah Principal Componen Analysis (PCA) . hasilnya dapat dilihat pada tabel 2 berikut ini.

\begin{tabular}{|l|r|r|r|c|}
\hline \multirow{2}{*}{ Faktor } & \multicolumn{4}{|c|}{ Initial Eigenvalues } \\
\cline { 2 - 5 } & $\begin{array}{c}\text { Nilai } \\
\text { eigen }\end{array}$ & $\begin{array}{c}\text { Keraga } \\
\text { man } \\
\text { total }(\%)\end{array}$ & $\begin{array}{c}\text { Keraga } \\
\text { man } \\
\text { total } \\
\text { komula } \\
\text { tif }(\%)\end{array}$ & Status \\
\hline 1 & 2.935 & 18.343 & 18.343 & Digunakan \\
\hline 2 & 1.590 & 9.936 & 28.279 & Digunakan \\
\hline 3 & 1.552 & 9.701 & 37.980 & Digunakan \\
\hline 4 & 1.282 & 8.014 & 45.993 & Digunakan \\
\hline 5 & 1.165 & 7.284 & 53.277 & Digunakan \\
\hline 6 & 1.023 & 6.394 & 59.671 & Digunakan \\
\hline
\end{tabular}

Berdasarkan diatas dapat diketahui bahwa jumlah faktor yang terbentuk berdasarkan nilai eigenvalue> 1 adalah 6 faktor dengan nilai keragaman total komulatif sebesar 59,671\%. Dimana faktor I memiliki eigenvalue sebesar 2,935 dan keragaman total $18,343 \%$. Faktor II memiliki 


\section{CAPITAL \\ JURNAL EKONOMI DAN MANAJEMEN \\ P-ISSN: 2598-9022/ E-ISSN: 2598-9618 \\ Available at: http://e-journal.unipma.ac.id/index.php/capital}

eigenvalue sebesar 1,590 dan keragaman total 9,936\%. Faktor III memiliki eigenvalue sebesar 1,552 dan keragaman total $9,701 \%$. Faktor IV memiliki eigenvalue sebesar 1,282 dan keragaman total $8,014 \%$. Faktor V memiliki eigenvalue sebesar 1,165 dan keragaman

\begin{tabular}{|c|c|c|c|}
\hline I & $\mathrm{X} 16$ & Proses kredit cepat & 0.726 \\
\hline & $\mathrm{X} 19$ & $\begin{array}{l}\text { Pelayanan sesuai dengan } \\
\text { jadwal }\end{array}$ & 0.668 \\
\hline & $\mathrm{X} 20$ & Respon karyawan & 0.560 \\
\hline $\mathrm{V}$ & $\mathrm{X} 12$ & $\begin{array}{l}\text { Pinjaman sesuai dengan } \\
\text { kebutuhan }\end{array}$ & 0.791 \\
\hline & $\mathrm{X} 13$ & Jaminan fleksibel & 0.678 \\
\hline $\begin{array}{l}\mathrm{V} \\
\mathrm{I}\end{array}$ & X9 & $\begin{array}{l}\text { Kekurangan persyaratan } \\
\text { menyusul }\end{array}$ & 0.837 \\
\hline
\end{tabular}

Sumber : data primer diolah, 2019. total $7,284 \%$ dan faktor VI memiliki eigenvalue sebesar 1,023 dengan keragaman total $6,394 \%$.

Setelah ke-enam faktor sudah terbentuk maka langkah selanjutnya adalah mengelompokkan beberapa variabel kedalam faktor tersebut. Metode yang digunakan adalah Rotated Component Matrix. Variabel yang mengelompok pada ke enam faktor tersebut haruslah memiliki nilai faktor loading lebih dari 0,5. Tabel rotated component matrix disajikan dalam lampiran 1 sedangkan Hasil rotasi untuk mengetahui pengelompokkan faktor dapat dilihat pada tabel 3 dibawah ini.

Tabel 5. Hasil Ekstraksi Faktor

\begin{tabular}{|c|c|c|c|}
\hline $\begin{array}{l}\mathrm{F} \\
\mathrm{a} \\
\mathrm{kt} \\
\text { or }\end{array}$ & $\begin{array}{l}\text { Kod } \\
\text { e }\end{array}$ & Variabel & $\begin{array}{l}\text { Loading } \\
\text { Faktor }\end{array}$ \\
\hline \multirow[t]{3}{*}{$\mathrm{I}$} & $\mathrm{X} 5$ & Jangka waktu variasi & 0.748 \\
\hline & $\mathrm{X} 10$ & $\begin{array}{l}\text { Nominal pinjaman cukup } \\
\text { besar }\end{array}$ & 0.613 \\
\hline & $\mathrm{X} 17$ & Pelayanan yang ramah & 0.538 \\
\hline \multirow[t]{3}{*}{ II } & $\mathrm{X} 3$ & Alasan suku bunga & 0.551 \\
\hline & X6 & Potongan pelunasan & 0.746 \\
\hline & $\mathrm{X} 7$ & Persyaratan yang mudah & 0.706 \\
\hline \multirow{2}{*}{$\begin{array}{l}\text { II } \\
\text { I }\end{array}$} & $\mathrm{X} 2$ & Suku bunga variasi & 0.773 \\
\hline & $\mathrm{X} 4$ & Jangka waktu fleksibel & 0.748 \\
\hline
\end{tabular}

\section{PEMBAHASAN}

Jangka waktu kredit yang ditawarkan oleh BPR Kota Kediri bervariasi mulai dari jangka pendek yaitu 1 tahun hingga yang jangka panjang lebih dari 3 tahun. Hal ini dapat memberikan referensi bagi nasabah karena terdapat beberapa pilihan dan mereka bisa menyesuaikan sesuai dengan kemampuannya karena jangka waktu juga berhubungan dengan angsuran yang dibayarkan setiap bulannya.

Nasabah kadang juga menginginkan bank yang dapat meminjami kredit dengan nominal yang cukup besar. Hal ini terjadi karena umumnya mereka memiliki jamnan yang terbatas jumlahnya oleh karenanya jika bank hanya meminjamkan sedikit maka dia harus mencari pinjaman lain untuk menambah nominal tersebut tetapi jaminannya tidak ada lagi. Pelayanan yang diberikan petugas juga mendukung 


\section{JURNAL EKONOMI DAN MANAJEMEN \\ P-ISSN: 2598-9022/ E-ISSN: 2598-9618 \\ Available at: http://e-journal.unipma.ac.id/index.php/capital}

terciptanya suasana yang kekeluargaan sehingga nasabah merasa nyaman dalam bertransaksi dengan bank tersebut.nasabah selalu mengharapkan pelayanan yang berkualitas dari petugas bank agar dia semakin yakin terhadap pilihannya. Suyanto dkk (2003) menjelaskan bahwa pelayanan adalah salah satu kunci utama bagi nasabah dalam memutuslan mengambil kredit. Disamping itu sebagian besar nasabah memang saat ini sudah cerdas dalam memilih kredit, mereka tentu akan mencari bank yang mampu memberikan kredit dengan suku bunga yang cukup rendah dan ini juga menjadi alasan utama bagi mereka.

Potongan pada saat pelunasan juga menjadi daya tarik tersendiri bagi nasabah pasalnya dengan cara ini nasabah dapat termotivasi untuk segera melunasi pinjamannya dan mungkin juga akan meminjam lagi. Disisi lain bagi bank juga bermanfaat karena menghindari kredit macet dari nasabah sehingga operasional bank bisa berjalan lancar.

Persyaratan kredit yang mudah dalam hal ini tentu bank harus menyederhanakan persyaratan yang harus disiapkan nasabah untuk meminjam. Karena tidak semua nasabah memiliki persyaratan yang lengkap misalnya saja persyaratan administratif seperti KTP dan Kartu Keluarga yang kadang belum diperbaharui maka bank harus memberikan solusi agar nasabah tetap bisa mengajukan pinjaman.

Suku bunga yang bervariasi harus ditawarkan oleh bank kepada nasabah secara terbuka dan meyakinkan mereka untuk tetap bisa memilih jenis kredit dengan suku bunga tertentu. Suku bunga yang bervariasi untuk jenis tabungan juga digunakan untuk dayatarik nasabah agar mau menabung (Sunariyah,2004: 81).

Jangka waktu yang fleksibel dalam kredit memberikan kelonggaran bagi nasabah untuk menyesuaikan keinginannya dalam melakukan pelunasan. Ada nasabah yang ingin jangka waktu sangat pendek misalnya kurang dari satu tahun dengan alasan kredit yang dia pinjam hanya untuk acara terntu dan akan segera dikembalikan sebelum satu tahun. Hal tersebut menuntut bank untuk mampu memberikan penjelasan mengenai pemilihan jangka waktu kredit.

Hasil penelitian Sari (2014) menyebutkan bahwa secara parsial variabel suku bunga, pelayanan, jangka waktu dan jaminan kredit berpengaruh 
signifikan terhadap keputusan nasabah dalam mengambil kredit di bank. Proses kredit yang cepat juga menjadi salah satu alasan nasabah dalam mengambil kredit. Kebutuhan nasabah yang sifatnya mendesak menjadi faktor utama nasabah untuk mencari bank yang mampu memberikan kredit secara cepat. Ini yang harus benar-benar dimanfaatkan oleh bank karena tidak sedikit nasabah terjebak pada lembaga keuangan non bank yang notabene mampu merealisasikan kredit kurang dari 2 jam dengan konsekuensi biasanya bunganya lebih tinggi dibandingkan dengan bank.

Pelayanan kantor sesuai dengan jadwal. Hal ini kembali lagi terkait dengan masalah pelayanan dimana bank harus mampu mengakomodir kepentingan nasabah. Kadang ada nasabah yang dating terlalu pagi dimana jam operasional bank belum dibuka namun ada pula yang menginginkan datang ke kantor untuk realisasi kredit pada siang hari. Hal tersebut terkait dengan pekerjaan dari nasabah biasanya yang datang pagi mereka berniat sebelum bekerja mampir ke bank untuk relasisasi kredit dan yang datang siang mereka memiliki pekerjaan yang dikerjakan sejak pagi misalnya saja petani.
Respon karyawan terhadap nasabah harus dilakukan setiap waktu. Misalnya saja untuk menghadapi kondisi diatas jika nasabah tidak bisa datang kekantor pagi hari mungkin bank bisa memberikan kelonggaran namun dengan batas waktu yang telah disepakati karena terkait dengan operasional kantor agar berjalan lancer. Petugas harus mampu merespon setiap masalah yang dihadapi oleh nasabah dan tentu dengan memberikan solusinya secara cepat.

Pinjaman sesuai dengan kebutuhan. Pada umumnya nasabah selalu mengajukan pinjaman dengan nominal besar dan tidak jarang melebihi dari taksasi jaminan yang dimiliki. Oleh karenanya pertugas perlu melakukan taksasi jaminan secara detail dengan mengetahui harga pasaran dari jaminan tersebut. Kemudian memberikan menanyakan kepada nasabah terkait kegunaan kredit yang diajukan dan menyarankan agar kredit yang dipinjam sesuai dengan kebutuhan.

Jaminan yang fleksibel. Petugas bank harus mampu memberikan taksasi yang benar terkait dengan jaminan yang diberikan oleh nasabah. Misalnya saja untuk jaminan sertifikat hak milik (SHM) petugas memiliki patokan bahwa harga tanah setiap tahunnya naik dan 


\section{JURNAL EKONOMI DAN MANAJEMEN \\ P-ISSN: 2598-9022/ E-ISSN: 2598-9618 \\ Available at: http://e-journal.unipma.ac.id/index.php/capital}

jenis bangunan juga mempengaruhi maka nilai taksasi bisa dilonggarkan sesuai dengan kebutuhan nasabah dengan catatan nasabah memiliki rekam jejak yang baik terhadap bank berbeda dengan jaminan BPKB kendaraan bermotor yang nilainya setiap tahun menurun maka petugas juga harus menyesuaikan dengan kebutuhan nasabah dan bila kurang maka nasabah disarankan untuk menambah jaminan lagi.

Kekurangan persyaratan bisa menyusul. Jika persyaratan jaminan dari nasabah kurang karena kredit yang diminta lebih besar dari jaminan biasanya petugas bank menyarankan untuk menambah jaminan lagi. Namun hal ini membutuhkan waktu lagi sedangkan nasabah biasanya tidak banyak memiliki waktu karena urusan usaha dan ataupun kepengtingan kerja lainnya. Maka bank harus memberikan solusi kepada nasabah apalagi jika nasabah ini memiliki karakter yang baik dan sudah meminjam berkali-kali dengan angsuran yang lancar, ini tentu termasuk dalam jenis konsumen yang potensial.

Beberapa variabel yang nilai MSA nya kurang dari 0,5 yaitu variabel $\mathrm{X} 1$ (suku bunga rendah), variabel $\mathrm{X} 8$ (persyaratan fleksibel), Variabel X14 (jaminan bervariasi) dan variabel X15 (jaminan sesuai kepemilikan). Suku bunga yang sangat rendah kadang tidak menjadi alasan bagi nasabah untuk mengambil kredit terutama jika itu ditawarkan oleh lembaga keuangan non bank. Misalnya persyaratan yang fleksibel mungkin tidak bisa ditawarkan oleh bank karena untuk mengajukan kredit umumnya persyaratan minimal yang harus dipenuhi nasabah sudah diatur oleh Bank Indonesia meliputi KTP, KK dan NPWP ini sebagai identitas dari nasabah jika salah satu saja kurang maka kredit tidak bisa diproses. Untuk jaminan yang bervariasi tidak menjadi faktor utama dalam mengambil keputusan kredit dikarenakan sebagian besar nasabah mungkin hanya memiliki satu atau dua jenis jaminan saja sehingga bagi mereka meskipun bank menawarkan banyak jaminan tidak akan berpengaruh dalam pengambilan keputusan untuk kredit. Jaminan sesuai kepemilikan tereliminasi dan tidak menjadi faktor utama karena terdapat beberapa jaminan terutama BPKB bukan atas nama sendiri hal ini terjadi karena mereka membeli kendaraan bermotor dari orang lain namun belum sempat 


\section{JURNAL EKONOMI DAN MANAJEMEN \\ P-ISSN: 2598-9022/ E-ISSN: 2598-9618 \\ Available at: http://e-journal.unipma.ac.id/index.php/capital}

dibalik nama namun sudah atas nama sendiri.

\section{SIMPULAN}

Berdasarkan analisis dan pembahasan diatas dapat disimpulkan bahwa terdapat 6 faktor utama nasabah dalam mengambil keputusan untuk kredit di BPR Kota Kediri diantaranya

1. Faktor I terdiri dari X5 (jangka waktu bervariasi), X10 (nominal pinjaman yang cukup besar) dan X17 (pelayanan yang ramah)

2. Faktor II terdiri dari X3 (alasan suku bunga), X6 (potongan pelunasan) dan $\mathrm{X} 7$ (persyaratan yang mudah)

3. Faktor III terdiri dari X2 (suku bunga bervariasi) dan X4 (jangka waktu fleksibel)

4. Faktor IV terdiri dari X16 (proses kredit cepat) dan X19 (pelayanan sesuai dengan jadwal)

5. Faktor $\mathrm{V}$ terdiri dari $\mathrm{X} 12$ (pinjaman sesuai dengan kebutuhan) dan X13 (jaminan fleksibel)

6. Faktor VI hanya satu variabel saja yaitu X9 (kekurangan persyaratan menyusul)
SARAN

Berdasarkan simpulan diatas maka disarankan bagi pihak BPR Kota Kediri untuk senantiasa merespon perubahan cepat yang ada disekitarnya terutama yang berasal dari nasabah. Petugas bank harus mampu melayani nasabah sebaik mungkin dengan mendasarkan pada keinginan dan kebutuhannya namun juga tetap mengacu pada aturan yang telah ditetapkan oleh bank tersebut. Dengan begitu diharapkan kesetiaan nasabah akan tetap terjaga dan kedepannya bisa mendapatkan nasabah yang lebih banyak lagi karena nasabah lama yang terlayani dengan baik tentu akan memberikan rekomendasi kepada calon nasabah baru.

\section{DAFTAR PUSTAKA}

Bramantyo, Anaga (2017). Pengaruh kualitas layanan, prosedur kredit, danPromosi terhadap keputusan kredit UMKM.Jurnal Profita edisi 5 universitas negeri Yogyakarta ISSN : 24770159

Anam, Khoiru A dan Nahar A (2015). Identifikasi model pembiayaan usaha kecil dan menengah oleh Lembaga Keuangan Mikro di Kabupaten Jepara. Jurnal Universitas Islam Nahdatul Ulama Vol.1 No.1 ISSN: 2442$885 \mathrm{X}$ 


\section{CAPTTAL \\ JURNAL EKONOMI DAN MANAJEMEN \\ P-ISSN: 2598-9022/ E-ISSN: 2598-9618 \\ Available at: http://e-journal.unipma.ac.id/index.php/capital}

Ramdhansyah \& Sondang Silalahi. 2013.

Pengembangan Model

Sunariyah (2004). Pengantar

Pendanaan UMKMBerdasarkan

Persepsi UMKM. Jurnal

Keuangan dan Bisnis, Vol.5 (1): 30-40.

Sari, Fitri, R (2014). Analisis faktorfaktor yang mempengaruhi nasabah dalam mengambil kredit. Naskah publikasi.Universitas muhammadiyah Surakarta.

Sugiyono. 2013. Metode Penelitian Pendidikan Pendekatan Kuantitatif, Kualitatif, dan $R \& D$. Bandung: Alfabeta Pengetahuan pasar Modal.Edisi Kelima. Bandung: CV Alfabeta

Suyanto, Thomas dkk. 2003. Dasardasar Perkreditan. Jakarta : PT. Gramedia Pustaka Utama

https://www.merdeka.com/uang/keme nkop-baru-20-persen-umkm-yangmengakses-modal-lewat-bank.html diakses pada tanggal 9 Juli 2019

http://koranmemo.com/umkmberkembang-pesat-wali-kota-kediri/ diakses pada tanggal 10 Juli 2019 